\title{
Sex differences in plasma corticosterone in mouse fetuses are mediated by differential placental transport from the mother and eliminated by maternal adrenalectomy or stress
}

\author{
M. M. Montano ${ }^{1}$, M-H. Wang ${ }^{2}$ and F. S. vom Saal ${ }^{1,2 *}$ \\ ${ }^{1}$ Division of Biological Sciences, and ${ }^{2} J o h n$ M. Dalton Research Center, University of \\ Missouri-Columbia, Columbia, MO 65211, USA
}

\begin{abstract}
The effect of changes in maternal corticosterone concentrations, induced by maternal stress, maternal adrenalectomy or both, on concentration of corticosterone in serum and in adrenals of mouse (Mus domesticus) fetuses was examined. Higher baseline serum corticosterone concentrations were found in female fetuses than in male fetuses; however, there was no sex difference in the content of corticosterone in adrenals collected from these fetuses. Sex differences were observed in the fetal response to changes in maternal concentrations of serum corticosterone resulting from stress (bright light and heat) or adrenalectomy, and both factors eliminated the sex difference in corticosterone in fetal serum. When females were injected i.v. with $\left[{ }^{3} \mathrm{H}\right]$ corticosterone on day 17 of pregnancy, significantly more ${ }^{3} \mathrm{H}$ was recovered from the serum of female than of male fetuses 15 min after the injection, while more ${ }^{3} \mathrm{H}$ was recovered from placentae of male fetuses. This finding suggests that the difference in serum corticosterone in male and female mouse fetuses is due to greater transport of corticosterone from maternal blood across the placenta of female than of male fetuses.
\end{abstract}

\section{Introduction}

The fetal pituitary-adrenal system starts functioning between days 17 and 18 of pregnancy in rats (Dupouy et al,, 1975), and an important modulating role for corticosterone of maternal origin is well established (Yamamoto et al., 1983). In rats the fetal adrenals hypertrophy between day 18 and day 22 of pregnancy after maternal adrenalectomy on day 14 . This has been interpreted as a compensatory response of the fetal pituitaryadrenal axis to a fall in circulating glucocorticoids derived from an adrenalectomized mother; corticosterone, but not $\mathrm{ACTH}$ (which would be increased in mothers after adrenalectomy), crosses the placenta from the maternal to the fetal circulation (Zarrow et al., 1970; Wong and Burton, 1974; Dupouy et al, 1980).

The presence of glucocorticoid receptors in the placenta has been reported in rats (Heller et al., 1981, 1983) and mice (Wong and Burton, 1974). Glucocorticoids may play a role in the inhibition of placental progesterone secretion during midpregnancy (Heller and DeNicola, 1983). Most progesterone in the maternal circulation is secreted by the maternal ovaries (Pointis et al., 1981). The decrease in placental progesterone secretion that occurs at mid-pregnancy is associated with an induction of corticosterone metabolism by the placenta (Pepe and Albrecht, 1984), and, thus, a decrease in the passage of corticosterone from the maternal to the fetal circulation. In mice,

\section{${ }^{*}$ Correspondence.}

Revised manuscript received 15 June 1992. this occurs on day 11 (Montano et al., 1991), when there is a dramatic increase in corticosterone in maternal blood following a marked increase in placental androgen secretion on days 9 and 10 of pregnancy (Barkley et al., 1979; Soares and Talamantes, 1982, 1983; F. S. vom Saal, unpublished). Androgens synthesized by the placenta are secreted into maternal and fetal compartments and are substrates for oestrogen biosynthesis in the maternal ovary (Jackson and Albrecht, 1985; Gibori et al., 1988) and possibly also in fetuses (vom Saal et al., 1992). The dramatic changes in maternal glucocorticoid concentrations beginning during mid-pregnancy could influence steroid hormone (androgen, oestrogen, glucocorticoid) concentrations in the fetal circulation. In addition, it is possible that sex differences in placental binding or metabolism of corticosteroids could be due to serum differences in these steroids between male and female fetuses (Ward and Weisz, 1980; Wilke et al., 1982; vom Saal et al., 1990; Montano et al., 1991).

Changes in maternal glucocorticoid concentrations owing to maternal stress or maternal adrenalectomy also influence androgen and glucocorticoid concentrations in the fetal circulation (Ward and Weisz, 1980; vom Saal et al., 1990; Montano et al., 1991). We, therefore, examined the effects of changes in maternal concentrations of serum corticosterone induced by maternal stress, adrenalectomy, or both, on serum corticosterone concentrations and adrenal corticosterone content in male and female fetuses. We also examined the transport of $\left[{ }^{3} \mathrm{H}\right] \mathrm{corti}-$ costerone from the maternal circulation into male and female fetuses. 


\section{Materials and Methods}

\section{Animals}

CF- 1 mice were housed in $18 \mathrm{~cm} \times 29 \mathrm{~cm} \times 13 \mathrm{~cm}$ polypropylene cages on Aspen bedding. Mouse breeder chow (Purina 5008) and water were available ad libitum. Animal rooms were maintained at $23 \pm 2^{\circ} \mathrm{C}$ in a $12 \mathrm{~h}$ light:12 h dark cycle, with lights on at 12:00 h. The onset of the light phase of the cycle will be referred to as $00: 00 \mathrm{~h}$, and all times of day will be relative to the beginning of the light phase of the cycle. All work in the animal rooms during the dark phase of the cycle was conducted under a $25 \mathrm{~W}$ red light to which mice do not respond.

\section{Mating}

Adult CF- 1 female mice were mated by being placed with males for $4 \mathrm{~h}$ beginning at 21:00 h ( $3 \mathrm{~h}$ before the onset of the light phase of the light:dark cycle). Mating was confirmed by the presence of a copulatory plug and mated animals were considered to have been fertilized at the onset of the light phase at 00:00 h, which was thus labelled as the beginning (day 0) of pregnancy. Mated females were housed three per cage until assigned to a treatment group.

\section{Stress procedure}

Randomly selected pregnant females were stressed using procedures similar to those described by vom Saal et al. (1990). Pregnant females were placed in Plexiglas mouse restraining chambers $(9 \mathrm{~cm} \times 6.3 \mathrm{~cm} \times 5 \mathrm{~cm})$ under a bank of $150 \mathrm{~W}$ floodlights $\left(3760\right.$ lux at $\left.38^{\circ} \mathrm{C}\right)$. Females were stressed twice a day at 04:00 h and 20:00 h beginning at 20:00 h on day 12 of pregnancy. Each stress session lasted $45 \mathrm{~min}$. Control pregnant females were left undisturbed in their cages.

\section{Surgery and collection of blood samples}

Adrenalectomies were performed via the dorsal approach on the beginning of day 11 of pregnancy using inhalation of methoxyflurane (Metofane: Pitman-Moore, NJ) as an anaesthetic. All adrenalectomized females were housed singly and given access ad libitum to a solution of $1 \%$ saline (to compensate for the loss of aldosterone) and $0.5 \%$ dextrose (for palatability) in tap water.

Pregnant females from all groups were housed individually on day II of pregnancy. On different days of pregnancy, females were decapitated, and blood was collected in test tubes within $15 \mathrm{~s}$. All fetuses were removed from the uterine horns, and fetal blood was collected in heparinized micropipettes by aspiration after fetal decapitation (within 2 min of maternal decapitation). Fetal sex was determined by examining the length of the anogenital space, which unambiguously distinguishes males from females at the times examined in these studies. Blood from fetuses of each sex within a litter was pooled to control for litter effects. Fetuses were placed in ice until their adrenals were collected. The adrenals were frozen at $-70^{\circ} \mathrm{C}$ immediately after removal. Blood was centrifuged, and plasma frozen at $-70^{\circ} \mathrm{C}$ until assayed.
After decapitation and removal of fetuses, adrenalectomized females were autopsied and tissue around the area of the excised adrenal was collected and frozen. The tissue was extracted and assayed for the presence of corticosterone. There was no indication of residual corticosterone-secreting adrenal tissue in any of the animals.

\section{Preliminary study for residual corticosterone-secreting adrenal tissue after adrenalectomy}

A preliminary experiment was performed to determine whether residual adrenal cortical tissue was present after adrenalectomy. Virgin rather than pregnant females were used, as fetuses serve as a non-maternal source of corticosterone in plasma of pregnant females.

Ten virgin female mice were adrenalectomized at $12: 00 \mathrm{~h}$ (just before the end of the light phase of the cycle), and blood was collected by decapitation at either $24 \mathrm{~h}$ or $48 \mathrm{~h}(n=5$ females per group) after adrenalectomy for examination of concentrations of corticosterone in plasma. Tissue samples were also collected from around the dorsal aspect of the kidney and examined for the presence of corticosterone.

At $24 \mathrm{~h}$ after adrenalectomy, two out of five virgin females still exhibited concentrations of corticosterone in plasma ( $25 \mu \mathrm{g}$ in $100 \mathrm{ml}$ and $20 \mu \mathrm{g}$ in $100 \mathrm{ml}$ ) that were similar to the peak values observed in intact virgin females killed at the same time of day (Montano et al., 1991). The concentrations of corticosterone in plasma of the other three females were $30 \%$ lower than values observed in intact females. By $48 \mathrm{~h}$ after adrenalectomy, mean concentrations of corticosterone in plasma had fallen to $1.92 \pm 0.73 \mathrm{ng} \mathrm{ml}^{-1}, 92 \%$ lower than values observed in intact virgin female mice killed at the same time of day. Corticosterone was not detected in tissue samples collected along the anterior head of the kidney in any of the females used in this study. Taken together, these findings suggest that all corticosterone secreting adrenal tissue was removed during the adrenalectomy procedure.

\section{Extraction of steroids}

Corticosterone was extracted twice with $2 \mathrm{ml}$ of an ethylacetate:chloroform $(80: 20, \mathrm{v}: \mathrm{v})$ mixture, dried under nitrogen and reconstituted in $140 \mu \mathrm{l}$ buffer. It was necessary to dilute maternal plasma (1:40) in assay buffer to obtain values that fell within the range of the assay. Steroids were extracted from fetal adrenals in the same manner, except that there was a $36 \mathrm{~h}$ incubation after addition of the extraction mixture. Recovery was monitored by addition of 2800 d.p.m. (5 pg) of $\left[1,2,6,7-{ }^{3} \mathrm{H}\right]$ corticosterone $\left(85.8 \mathrm{Ci} \mathrm{mmol}^{-1}\right.$; New England Nuclear, Boston, MA) to control samples before extraction. A $20 \mu \mathrm{l}$ aliquot for recovery and duplicate $50 \mu \mathrm{l}$ aliquots for steroid radioimmunoassay were withdrawn after reconstitution. Recovery was routinely greater than $90 \%$.

\section{Corticosterone radioimmunoassay}

Corticosterone radioimmunoassay was performed as described in detail by Montano et al. (1991). Briefly, $\left[1,2,6,7{ }^{3} \mathrm{H}\right]$ corticoster- 
one (85.8 $\mathrm{Ci} \mathrm{mmol}^{-1}$ ) was obtained from New England Nuclear (Boston, MA), and unlabelled corticosterone was obtained from Steraloids, Inc. (Wilton, NH). Corticosterone antiserum (rabbit) was obtained from Gordon Niswender (Ft Collins, CO). Duplicate aliquots of $50 \mu \mathrm{l}$ of extracted steroid in buffer were incubated for $4 \mathrm{~h}$ at $24^{\circ} \mathrm{C}$ with 18000 d.p.m. $(33 \mathrm{pg})$ of $\left[{ }^{3} \mathrm{H}\right]$ corticosterone and antiserum to corticosterone. Free and bound steroids were separated by second antibody addition (diluted 1:11; goat, antirabbit; Radioassay Systems Laboratories, Inc., Carson, CA). Tubes were incubated overnight at $4^{\circ} \mathrm{C}$ and then centrifuged at $1500 \mathrm{~g}$ for $\mathrm{I} \mathrm{h}$. The supernatant was decanted, and the precipitate (representing the bound portion) was counted in a liquid scintillation counter (Beckman LS 5801, efficiency for tritium: $56 \%$ ) after addition of $5 \mathrm{ml}$ Scintiverse II (Fisher). The range of the standard curve for corticosterone was 60-2000 pg per tube. The blank of the assay was indistinguishable from baseline values. The inter- and intra-assay coefficients of variation were $11 \%$ and $2 \%$, respectively.

\section{Statistical analysis}

Serum and tissue corticosterone concentrations were compared by analysis of variance or analysis of covariance using the Statistical Analysis System (SAS, General Linear Model). Planned comparisons were made using the LS means test (SAS).

\section{Experimental Details and Results}

\section{Experiment 1: effect of adrenalectomy on day 11 on corticosterone concentrations in plasma of pregnant females}

The objective of this experiment was to assess when the adrenals of fetuses begin to secrete corticosterone by examining corticosterone concentrations in maternal blood after adrenalectomy on day 11 of pregnancy. Before day 16 of pregnancy, too little blood was collected from fetuses to assess directly the onset of secretion of corticosterone in fetuses.

Methods. Pregnant females were adrenalectomized at $00: 00 \mathrm{~h}$ on day 11 of pregnancy. Blood was collected for determination of concentrations of corticosterone in plasma at $00: 00 \mathrm{~h}$ just after the onset of the light phase of the light:dark cycle on days 14-18 of pregnancy. Blood was also collected from intact pregnant females at corresponding times. Seventyfive pregnant females were used.

Results. Analysis of variance performed on maternal serum corticosterone revealed a significant interaction between day and treatment $(P<0.001)$. Females adrenalectomized on day 11 of pregnancy showed serum corticosterone concentrations on day 14 that were $3 \%$ of the concentrations $(5.0 \pm 0.8 \mu \mathrm{g}$ in $\left.100 \mathrm{ml}^{-1}\right)$ observed in intact pregnant females $(153 \pm 7 \mu \mathrm{g}$ in $100 \mathrm{ml}^{-1}$ ). An increase in plasma corticosterone was observed on day 15 , followed by concentrations on day 16 that were not significantly different from those of intact pregnant females (Fig. 1). Adrenalectomized females had significantly higher concentrations of corticosterone in plasma than did intact females on day $17(P<0.01)$ and day $18(P<0.05)$.

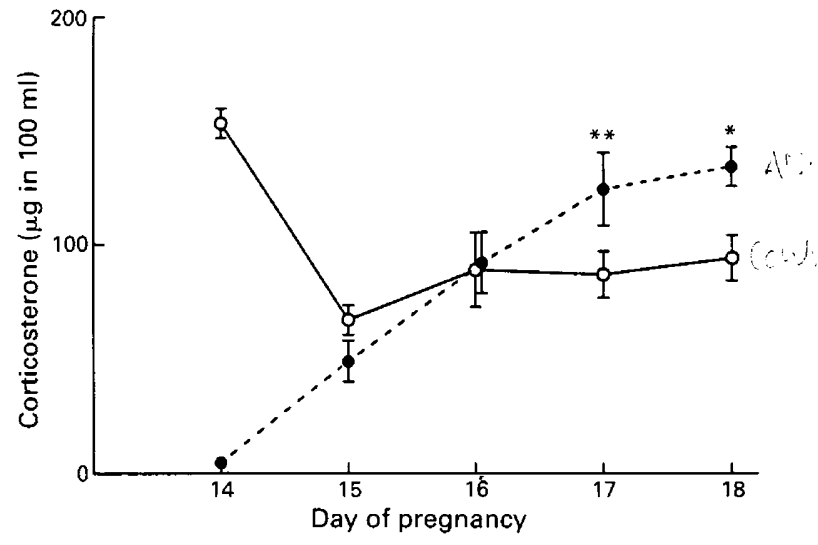

Fig. 1. Concentrations of corticosterone in plasma (mean \pm SEM) in (O) intact and (O) adrenalectomized (ADX) (on day 11) pregnant females at $00: 00 \mathrm{~h}$ on days 14-18 of pregnancy. Number of samples assayed for successive time points were: intact 5, 6, 7, 13 and 12; adrenalectomized: $6,5,5,11$ and 5 . ${ }^{*}$ Significant difference between intact and adrenalectomized females $(P<0.05)$. ${ }^{* *}$ Significant difference between intact and adrenalectomized females $(P<0.01)$.

\section{Experiment 2: effect of maternal adrenalectomy on day 11 or stress on corticosterone in maternal and fetal serum and fetal adrenal glands}

In this experiment, the fetal response to maternal adrenalectomy, stress and a combination of adrenalectomy and stress on day 18 of pregnancy were determined. Eighteen-day-old fetuses were used as the previous experiment showed evidence of hypersecretion by the fetal adrenals on day 18 following maternal adrenalectomy on day 11 , and a much greater volume of plasma can be obtained from fetuses on day 18 than on day 17 of pregnancy.

Methods. Pregnant females were adrenalectomized on day 11. Half of the adrenalectomized females, and half of the group of intact females were subjected to stress twice each day, starting at 20:00 h on day 13. This was to allow sufficient time for recovery after adrenalectomy. A group of adrenalectomized and intact females was left undisturbed until the time of blood and tissue collection (referred to as control-adrenalectomized and control-intact females, respectively).

Blood was collected from stressed and control animals at $00: 00 \mathrm{~h}$ on day $18,4 \mathrm{~h}$ after the onset of the last stress session, which began at 20:00 h on day 17 during the dark phase of the light:dark cycle. We previously observed that concentrations of corticosterone in plasma were relatively low at $00: 00 \mathrm{~h}$ on day 18 in intact, non-stressed mouse fetuses (Montano et al., 1991). Thirty-five litters were used.

Results. Control-adrenalectomized mothers again showed higher concentrations of corticosterone relative to controlintact mothers, although the difference was not statistically significant. As expected, there was no significant difference in plasma corticosterone between stressed-adrenalectomized and control-adrenalectomized pregnant females. However, there tended to be an increase $(P=0.07)$ in serum corticosterone in stressed-intact mothers relative to control-intact mothers $4 \mathrm{~h}$ 


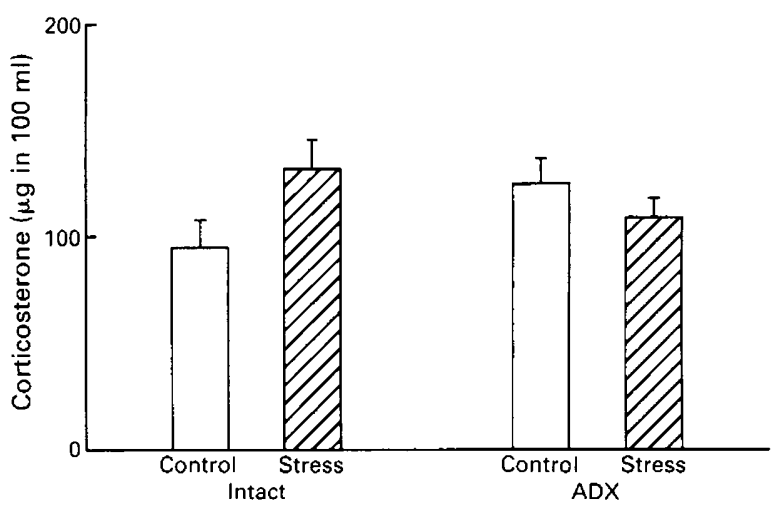

Fig. 2. Concentrations of corticosterone in plasma (mean + SEM) in intact and adrenalectomized (on day 11) pregnant females at 00:00 h on day 18 of pregnancy. Stress $(\nabla)$ : stressed twice a day starting on day 13. Control $(\square)$ : left undisturbed until collection of blood samples. Intact control, $n=6$; intact stress, $n=13$; adrenalectomized (ADX) control, $n=6$; adrenalectomized stress, $n=10$.

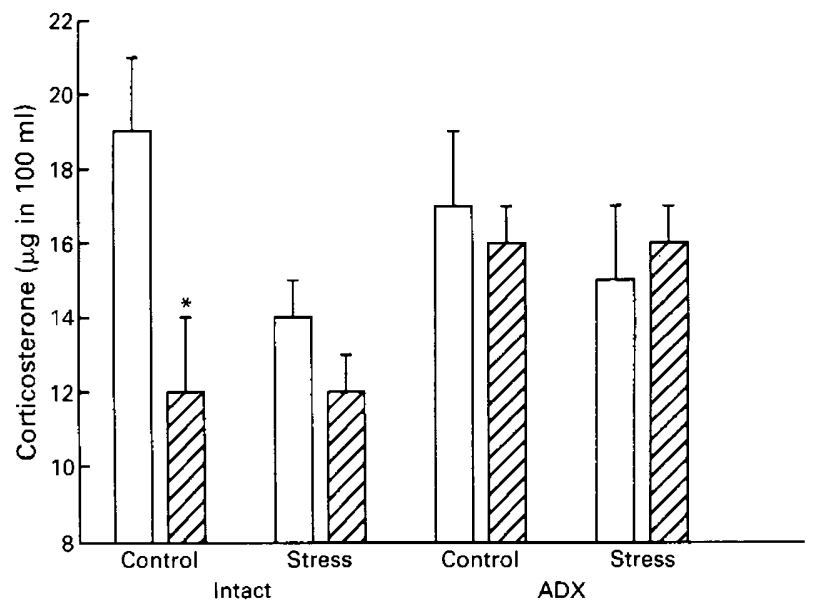

Fig. 3. Concentrations of corticosterone in plasma (mean + SEM) on day 18 of pregnancy at $00: 00 \mathrm{~h}$ in male and female fetuses carried by intact and adrenalectomized (ADX) (on day 11) mothers. Stress: mothers were stressed twice a day starting on day 13. Control: mothers were left undisturbed until sample collection. The following number of samples were assayed (representing pooled sera from fetuses of the same sex in each litter): male fetuses $(\nabla)$ : intact control, $n=7$; intact stress, $n=15$; adrenalectomized control, $n=9$; adrenalectomized stress, $n=9$; female fetuses $(\square)$ : intact control, $n=8$; intact stress, $n=11$; adrenalectomized control, $n=7$; adrenalectomized stress, $n=8$. *Significant difference between male and female fetuses $(P<0.01)$.

after the last stress session (Fig. 2), which was consistent with previous findings (Montano et al., 1991).

In fetuses from intact, control mothers, females had significantly $(58 \%)$ higher concentrations of corticosterone in plasma than did males ( $P<0.01$; Fig. 3 ). However, no sex difference in fetal adrenal corticosterone content was observed in these fetuses (Fig. 4). Maternal stress induced a decrease in serum corticosterone concentrations relative to control fetuses from

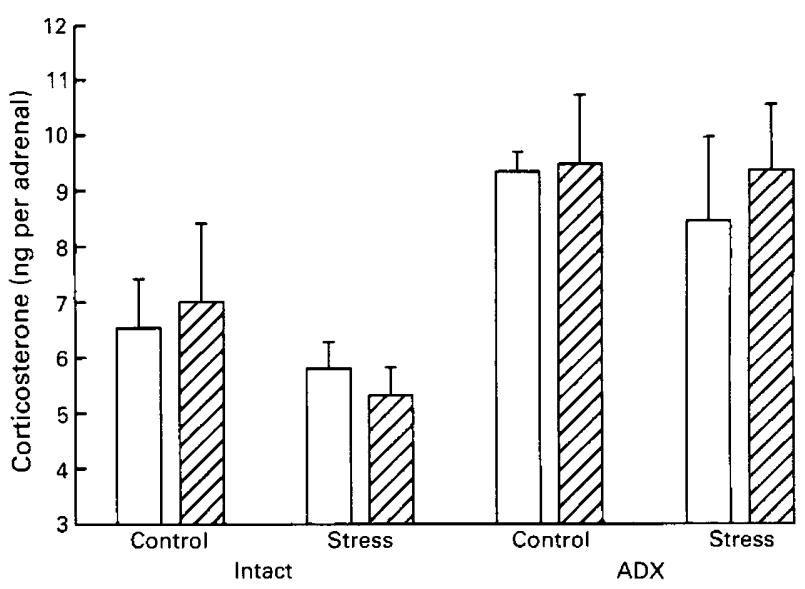

Fig. 4. Corticosterone content (mean + SEM) in adrenal glands collected on day 18 of pregnancy at $00: 00 \mathrm{~h}$ from male and female fetuses carried by intact and adrenalectomized (ADX) (on day 11) mothers. Stress: mothers were stressed twice a day starting on day 13. Control: mothers were left undisturbed until sample collection. Each sample consisted of paired adrenals pooled from four fetuses of the same sex in each litter. The following number of samples were assayed: male fetuses $(\bigotimes)$ : intact control, $n=7$; intact stress, $n=15$; adrenalectomized control, $n=9$; adrenalectomized stress, $n=9$; female fetuses $(\square)$ : intact control, $n=8$; intact stress, $n=11$; adrenalectomized control, $n=7$; adrenalectomized stress, $n=8$.

intact mothers only in female fetuses: corticosterone decreased $(P<0.05)$ to control male values (Fig. 3). In both male and female fetuses from intact mothers, only a slight but nonsignificant decrease in adrenal corticosterone content was observed as a result of maternal stress (Fig. 4).

Maternal adrenalectomy induced an increase in serum corticosterone concentrations in male fetuses $(P<0.05)$ but not in female fetuses. In contrast, there was a significant difference in adrenal corticosterone content in fetuses (regardless of sex) from intact versus adrenalectomized mothers $(P<0.01)$.

\section{Experiment 3: effect of adrenalectomy on day 16 of pregnancy on corticosterone in plasma of pregnant mothers and fetuses}

The results of Expt 1 suggested that fetuses begin secreting corticosterone as early as days 14-15 of pregnancy. Furthermore, the high corticosterone concentrations in maternal serum on day 17 and 18 following adrenalectomy on day 11 appeared to reflect hypersecretion of corticosterone by the fetal adrenals, since adrenal corticosterone content was high in both male and female fetuses carried by adrenalectomized mothers (Expt 2). The objective of this experiment was to determine whether hypersecretion by the fetal adrenals on day 18, which was observed after maternal adrenalectomy on day 11 in Expt 1 , required 6-7 days or would also be observed within 1-2 days after maternal adrenalectomy on day 16 .

Methods. Pregnant females were adrenalectomized on day 16 of pregnancy at 00:00 h. Separate groups of females were killed at 00:00 h on day 17 and day 18, and blood was collected from both the pregnant females and their fetuses. 


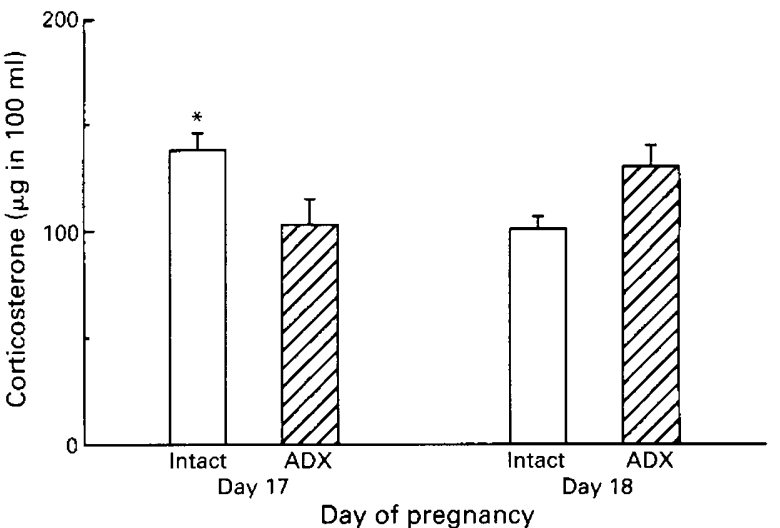

Fig. 5. Concentrations of corticosterone in plasma (mean + SEM) in intact ( $\square$ ) and adrenalectomized ( $\nabla$ ) (on day 16) pregnant females at $00: 00 \mathrm{~h}$ on day 17 and day 18 of pregnancy. Control: left undisturbed until blood collection. The following number of samples were assayed: day 17: intact, $n=5$; adrenalectomized, $n=7$; day 18: intact, $n=6$; adrenalectomized (ADX), $n=4$. "Significant difference between intact and adrenalectomized pregnant female $(P<0.01)$.

Results. Analysis of variance performed on concentrations of corticosterone in plasma of mothers revealed a significant interaction between day and treatment $(P<0.01 ;$ Fig. 5$)$. After adrenalectomy on day 16 , significantly higher concentrations of corticosterone in plasma were observed on day 17 of pregnancy in intact (control) pregnant females relative to adrenalectomized pregnant females $(P<0.05)$. Corticosterone in plasma tended to be higher on day 18 in adrenalectomized females relative to control females $(P=0.07)$.

Analysis of serum corticosterone concentrations on day 17 and 18 in fetuses revealed significant main effects of day and treatment (day: $P<0.01$; treatment: $P<0.05$ ). Overall, concentrations of corticosterone in plasma were lower on day 18 than on day 17 (Fig. 6). Irrespective of day of pregnancy, male fetuses from adrenalectomized mothers showed significantly higher $(P<0.01)$ concentrations of corticosterone in plasma than did male fetuses from intact mothers, whereas there was no significant difference in concentrations of corticosterone in plasma of female fetuses from adrenalectomized versus intact mothers. Concentrations of corticosterone in plasma of female fetuses from intact mothers were $34 \%$ higher than concentrations of corticosterone in plasma from male fetuses on day 18 , but the difference was not statistically significant.

\section{Experiment 4: transport of $\left.\mathrm{I}^{3} \mathrm{H}\right]$ corticosterone across the placenta from maternal to fetal blood}

In Expt 2 we observed that female fetuses had higher concentrations of corticosterone in plasma than did males, whereas the adrenal content of corticosterone was virtually identical in these males and females. Changes in corticosterone concentrations of maternal plasma (induced by maternal adrenalectomy, stress or a combination of both) led to markedly different effects on corticosterone in plasma of male and female fetuses. However, there was no difference between male and female fetuses in adrenal corticosterone content in response to these manipulations. These findings suggest that the sex difference in corticosterone of plasma in fetuses observed on day 18 , as well as

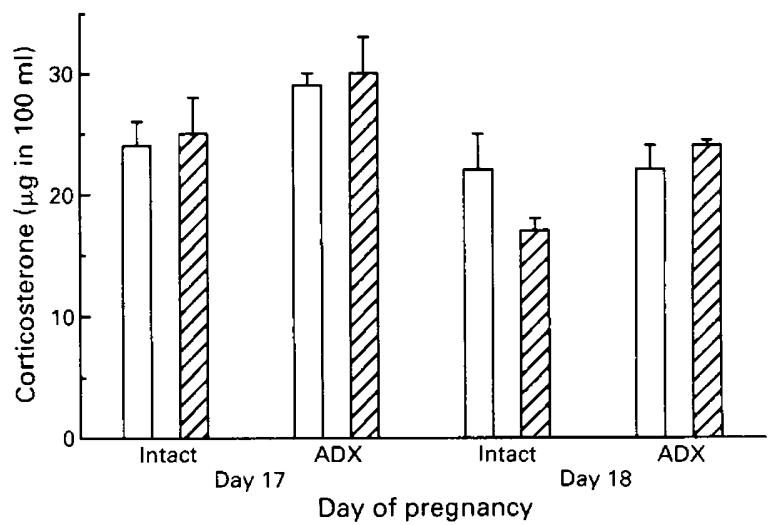

Fig. 6. Concentrations of corticosterone in plasma (mean + SEM) at 00:00 h on day 17 and 18 of pregnancy in male ( $(\nabla)$ and female $(\square)$ fetuses carried by intact and adrenalectomized (ADX) (on day 16) mothers. Control: mothers were left undisturbed until collection of sample. The following number of samples (representing pooled plasma from fetuses of the same sex in each litter) were assayed: male fetuses: day 17: intact, $n=7$; adrenalectomized (ADX), $n=7$; day 18: intact, $n=5$; adrenalectomized, $n=4$; female fetuses: day 17 : intact, $n=7$; adrenalectomized, $n=5$; day 18 intact, $n=6$; adrenalectomized, $n=4$.

the sex difference in response to maternal stress and adrenalectomy, is not due to a sex difference in the functioning of the brain-pituitary-adrenal axis during fetal life. We therefore examined the possibility that there are differences in placental transport and placental binding of corticosterone between male and female fetuses.

Methods. We injected $5 \mu \mathrm{Ci}$ (17 ng) of $1,2,6,7\left[^{3} \mathrm{H}\right]$ corticosterone (101.6 Ci mmol ${ }^{-1}$; New England Nuclear, Boston, $\mathrm{MA}$ ) in $100 \mu \mathrm{l}$ saline (with $2 \%$ ethanol) into the tail vein of female mice at 04:00 h on day 18 of pregnancy. In a previous study we observed a significant difference in concentrations of corticosterone in plasma between male and female fetuses at this time (Montano et al., 1991).

Pregnant females were decapitated, and trunk blood was collected 15-20 min after injection of $\left[{ }^{3} \mathrm{H}\right]$ corticosterone into the tail vein and within $15 \mathrm{~s}$ of the cage being touched. In a preliminary study the highest amount of radioactivity was found in fetal plasma at $15-20 \mathrm{~min}$ (relative to 60 or $120 \mathrm{~min}$ ) after i.v. injection of $\left[{ }^{3} \mathrm{H}\right]$ corticosterone into pregnant females.

Sixty fetuses (25 males and 35 females) from six litters were examined. All fetuses were removed from the uterine horns. Male and female fetuses were identified by examining anogenital distance, and blood was collected from individual fetuses in heparinized micropipettes by aspiration after fetal decapitation within $2 \mathrm{~min}$ of maternal decapitation. The placenta from each fetus was weighed and placed in a $20 \mathrm{ml}$ scintillation vial in an ice bath.

Blood from individual fetuses was centrifuged at $1000 \mathrm{~g}$ for $30 \mathrm{~min}$, and duplicate $10 \mu \mathrm{l}$ aliquots were placed in $5 \mathrm{ml}$ scintillation vials. Triplicate aliquots of the injection solution were also placed in scintillation vials and scintillation fluid was added for reference counting. Placentae were solubilized in $1 \mathrm{ml}$ of Soluene-350 (Packard) at $50^{\circ} \mathrm{C}$ for $1 \mathrm{~h}$. After addition of scintillation fluid to vials containing plasma and placental samples, the 
samples (including reference vials) were counted in a Beckman LS-5801 counter. Parameters were programmed in the liquid scintillation counter so that quench corrections were performed automatically for each sample.

Since metabolites of $\left[{ }^{3} \mathrm{H}\right]$ corticosterone were not recovered, the d.p.m. recovered from placentae and plasma will be referred to as $\left[{ }^{3} \mathrm{H}\right]$. Pearson correlation coefficients were calculated for $\left[{ }^{3} \mathrm{H}\right]$ present in maternal serum, placentae and fetal plasma. The correlation coefficients were also calculated for both placental weight and the ratio of males and females within a litter and all of the above variables.

Results. There was an average of $11 \pm 0.7$ fetuses per litter, and number of male fetuses:number of female fetuses was $0.71 \pm 0.1$. Sex ratio was not significantly correlated with placental weight, $\left[{ }^{3} \mathrm{H}\right]$ in placentae or $\left[{ }^{3} \mathrm{H}\right]$ in fetal blood. Male placentae were $10.6 \%$ heavier than female placentae (males = $89.9 \pm 2.9 \mathrm{mg}$; females $=81.3 \pm 2.8 \mathrm{mg} ; P<0.05$ ) whether analysed by ANOVA or using sex ratio as the covariate.

Correlation analysis $(n=70)$ showed that placental weight was the greatest predictor of $\left[{ }^{3} \mathrm{H}\right]$ in the placentae $(r=0.68$, $P<0.001$ ). When analysed by analysis of covariance using sex ratio as the covariate, $\left[{ }^{3} \mathrm{H}\right]$ recovered from male placentae (15 500 d.p.m.) was $14 \%$ higher than from female placentae (13 574 d.p.m.; $P=0.06$ ), suggesting greater binding of corticosterone in placentae of male fetuses, although when analysed by ANOVA this sex difference was not as great $(P=0.12)$.

Radioactivity in fetal plasma (males $=118571$ d.p.m. in $10 \mu \mathrm{l}$ plasma; females $=107895$ d.p.m. in $10 \mu \mathrm{l}$ plasma) was significantly correlated with $\left[{ }^{3} \mathrm{H}\right]$ in maternal plasma $(r=0.79$, $P<0.001$ ). The ratio of $\left[{ }^{3} \mathrm{H}\right]$ in fetal plasma: $\left[{ }^{3} \mathrm{H}\right]$ in maternal plasma was significantly ( $15 \% ; P<0.05)$ higher for female than for male fetuses, suggesting a greater transport of corticosterone from maternal plasma into female than into male fetuses.

\section{Experiment 5: adrenal weight and content of corticosterone in adult male and female mice}

Sex differences in adrenal weight and concentrations of corticosterone in plasma have been reported for some, but not all, breeds of mice (Shire, 1974). Since a sex difference in adrenal corticosterone content was not found in fetuses, adrenal weight and corticosterone content were compared in adult, virgin male and female CF-I mice to examine the possibility that this breed of mice does not show a sex difference in adrenal corticosterone content even in adulthood.

Methods. Animals of the same sex were housed four per cage from weaning until the day before being killed (when 90 days old), at which time each animal was individually housed. Animals were killed by cervical dislocation at 12:00 h (when peak values are observed in adult, virgin mice; Montano et al., 1991 ), and the adrenal glands were removed and weighed (24 animals were used).

Results. Analysis of variance revealed significantly (by $56 \%$ ) higher adrenal weights (mg per $100 \mathrm{~g}$ body weight for paired adrenals) in adult female mice than in adult male mice (females $=21.2 \pm 2.3 ;$ males $=13.6 \pm 0.9 ; P<0.01$ ). There was also a significant sex difference $(86 \%$ higher in females than in males) in adrenal corticosterone content (females $=110 \pm$ $3 \mathrm{ng}$ per adrenal; males $=59 \pm 6 \mathrm{ng}$ per adrenal; $P<0.01$ ). Concentrations of corticosterone in plasma were $116 \%$ higher in females than in males (females $=14.9 \pm 2.5 \mu \mathrm{g}$ in $100 \mathrm{ml}^{-1}$; males $=6.9 \pm 1.0 \mu \mathrm{g}$ in $100 \mathrm{ml}^{-1} ; P<0.01$ ).

\section{Discussion}

In female mice adrenalectomized on day 11 of pregnancy, plasma corticosterone increased from very low concentrations on day 14 to concentrations observed in intact pregnancy females by day 16 . It thus appears that by days 14-15 of pregnancy, secretion of corticosterone by the fetal adrenals begins and by day 16 can result in normal concentrations of corticosterone in maternal serum after maternal adrenalectomy. A rise in maternal serum corticosterone after maternal adrenalectomy in pregnant rats has been correlated with the onset of fetal brain-pituitary-adrenal activity, which has been reported to occur in rats between days 17 and 18 (Dupouy et al., 1975) or days 19 and 20 (Chatelain et al., 1980). Day 17-18 of pregnancy in rats roughly corresponds to days 16-17 of pregnancy in mice (Schlegel et al., 1967; Rugh, 1969). The time of onset of fetal brain-pituitary-adrenal activity suggested by our findings in mice is thus earlier than that observed in rats. The significantly higher concentrations of circulating corticosterone in adrenalectomized pregnant female mice relative to intact females on days 17 and 18 was unexpected and was not evident in previous studies with rats (Milkovic et al., 1973; Dupouy et al., 1975; Chatelain et al., 1980).

Adrenal content of corticosterone on day 18 of pregnancy was high in both male and female fetuses carried by mothers adrenalectomized on day 11 . This finding is consistent with the prediction that there should be an increase in the fetal secretion of corticosterone releasing factor (CRF; Chatelain et al., 1980), $\mathrm{ACTH}$ and corticosterone following a decrease in the fetal blood of corticosterone of maternal origin, since corticosterone, but not ACTH, can cross the placenta from the maternal to the fetal circulation (Dupouy et al., 1980). Steroids are not stored within cells that produce them. The rate of secretion of steroid hormones reflects the rate of synthesis and is correlated with organ content (Soares and Talamantes, 1983). It thus appears that the increase in adrenal corticosterone content at the single point measured in fetuses reflected an increase in the rate of synthesis and secretion of corticosterone by the fetal adrenal glands in response to maternal adrenalectomy.

A sex difference was not observed in adrenal corticosterone content of fetuses carried by either intact or adrenalectomized (on day 11) mothers. This finding suggests that there is no sex difference in fetal adrenal corticosterone synthesis or secretion. However, an increase (to control female values) in plasma corticosterone concentrations was observed on day 18 in male fetuses carried by mothers adrenalectomized on either day 11 (Expt 2) or day 16 (Expt 3), whereas no change was observed in concentrations of corticosterone in plasma of female fetuses after maternal adrenalectomy on either day. Maternal adrenalectomy, and the loss of corticosterone of maternal origin in the fetal blood, thus eliminated the difference in plasma corticosterone between male and female fetuses. 
There was an increase in corticosterone in maternal plasma $4 \mathrm{~h}$ after the onset of maternal stress (Expt 2). The increase in maternal corticosterone owing to stress led to a suppression of plasma corticosterone in female fetuses (to control male values). This finding suggests a suppression of corticosterone secretion by the adrenal glands of female fetuses carried by stressed mothers, but adrenal corticosterone content was only slightly (and not significantly) lower in stressed female fetuses relative to control female fetuses. In addition, a change in plasma corticosterone was not observed on day 18 in male fetuses when blood was collected $4 \mathrm{~h}$ after the onset of maternal stress, although their adrenal corticosterone content was slightly decreased relative to control male fetuses. The basis for these findings is unknown and contrasts with previous findings obtained one day earlier on day 17 of pregnancy in mice (Montano et al., 1991).

The only sex difference observed in any of these studies was in plasma corticosterone in fetuses carried by mothers that were not stressed or adrenalectomized. We thus hypothesized that a sex difference in the passage of corticosterone from the maternal circulation through the placenta might mediate the sex difference in circulating corticosterone in fetuses, perhaps via a difference between male and female fetuses in placental binding of corticosterone. Between 15 and $20 \mathrm{~min}$ after injection of $\left[{ }^{3} \mathrm{H}\right]$ corticosterone into pregnant females on day 18 , significantly (15\%) higher recovery of ${ }^{3} \mathrm{H}$ in female fetal plasma was observed when compared with male fetal plasma. This was accompanied by a $14 \%(P=0.06)$ higher degree of retention of ${ }^{3} \mathrm{H}$ in male versus female placentae.

The above finding provides evidence that the higher corticosterone concentrations in plasma of female fetuses compared with male fetuses is due to a greater passage of corticosterone from the maternal blood across the placenta of female relative to male fetuses, as there does not appear to be a sex difference in the capacity of the fetal adrenal glands to synthesize corticosterone. Total ${ }^{3} \mathrm{H}$ content in placentae and fetal blood only were examined and $\left[{ }^{3} \mathrm{H}\right]$-labelled metabolites were not identified; the possibility that there is a sex difference in placental or fetal corticosterone metabolism, or in both, cannot therefore be excluded. In contrast to our findings in male and female fetuses, adult, virgin female CF-1 mice had significantly higher adrenal corticosterone content (and heavier adrenal glands) than did adult males.

On day 18 of pregnancy in CF-1 mice, there are sex differences in circulating testosterone (male fetuses have higher testosterone than do female fetuses) and oestradiol (male fetuses have lower concentrations than do female fetuses; vom Saal et al., 1990). Sex differences in the plasma concentrations of gonadal steroids during fetal life may play a role in mediating the sex difference in placental transport of corticosterone from the maternal to the fetal circulation.

Corticosteroid-binding globulin is another factor that could play a role in mediating the sex difference in plasma corticosterone in fetuses, as well as in the endocrine response of male versus female fetuses to changes in maternal plasma corticosterone concentrations. This protein binds with high affinity to glucocorticoids and affects the clearance rate and the bioavailability of glucocorticoids during development. Sex differences were observed in changes in plasma corticosterone in response to maternal adrenalectomy and maternal stress only during periods where there were sex differences in control (baseline) plasma corticosterone concentrations. It remains to be determined whether a sex difference in corticosteroid-binding globulin concentrations in fetal plasma plays a role.

The experiments described here were approved by the Animal Care and Use Committee of the University of Missouri-Columbia. Support was provided by grants from NSF (DCB-9004806) and the University of Missouri Food for the Twenty-First Century Reproductive Biology Program to FSvS.

\section{References}

Barkley MS, Geschwind II and Bradford GE (1979) The gestational pattern of estradiol, testosterone, and progesterone secretion in selected strains of mice Biology of Reproduction 20 733-738

Chatelain A, Dupouy J and Allaume P (1980) Fetal-maternal adrenocorticotrophin and corticosterone relationships in the rat: effects of maternal adrenalectomy Endocrinology 106 1297-1303

Dupouy MJP, Coffigny H and Magre S (1975) Maternal and foetal corticosterone levels during late pregnancy in rats Joumal of Endocrinology 65 347-352

Dupouy MJP, Chatelain A and Allaume P (1980) Absence of transplacental passage of ACTH in the rat: direct experimental proof Biology of the Neonate 37 $96-102$

Gibori G, Khan I, Warshaw ML, McLean MP, Puryear TK, Nelson S, Durkee TJ, Azhar S, Steinschneider A and Rao MC (1988) Placental-derived regulators and the complex control of luteal cell function Recent Progress in Hormone Research $44377-429$

Heller C and De Nicola AF (1983) Inhibition of progesterone synthesis in placenta by administration of dexamethasone to pregnant rats Joumal of Steroid Biochemistry 19 1339-1343

Heller C, Coirini H and De Nicola AF (1981) Binding of ${ }^{3} \mathrm{H}$-dexamethasone by rat placenta Endocrinology 108 1697-1702

Heller C, Coirini H and De Nicola AF (1983) The placenta as a glucocorticoid target tissue: exchange assay of ${ }^{3} \mathrm{H}$-dexamethasone binding and effect of steroid on receptor content Hormone and Metabolism Research 15 41-45

Jackson JA and Albrecht ED (1985) The development of placental androstenedione and testosterone production and their utilization by the ovary for aromatization to estrogen during rat pregnancy Biology of Reproduction $33451-457$

Milkovic S, Milkovic K and Paunovic J (1973) The initiation of fetal adrenocorticotrophic activity in the rat Endocrinology 92 380-384

Montano MM, Wang MH, Even MD and vom Saal FS (1991) Serum corticosterone in fetal mice: sex differences, circadian changes, and effect of maternal stress Physiology and Behavior 50 323-329

Pepe GJ and Albrecht ED (1984) Comparison of the cortisol-cortisone interconversion in vitro by the human and baboon placenta Steroids 44 229-240

Pointis G (198I) Progesterone levels in the circulating blood of the ovarian and uterine veins during gestation in the mouse Biology of Reproduction 24 801-805

Rugh R (1969) The Mouse: Its Reproduction and Development. Burgess Publishing Co, Minneapolis

Schlegel RJ, Farias E, Russo NC, Moore JR and Gardner LI (1967) Structural changes in the fetal gonads and gonaducts during maturation of an enzyme, steroid $3 \beta$-ol-dehydrogenase, in the gonads, adrenal cortex and placenta of fetal rats Endocrinology $\mathbf{8 1} 565-572$

Shire JGM (1974) Endocrine genetics of the adrenal gland Journal of Endocrinology $62 \quad 173-207$

Soares MJ and Talamantes F (1982) Gestational effects on placental and serum androgen, progesterone and prolactin-like activity in the mouse Journal of Endocrinology 95 29-36

Soares MJ and Talamantes F (1983) Midpregnancy elevation of serum androstenedione levels in the $\mathrm{C} 3 \mathrm{H} / \mathrm{HeN}$ mouse: placental origin Endocrinology 113 1408-1412

vom Saal FS, Quadagno DM, Even MD, Keisler LW, Keisler DH and Khan SK (1990) Paradoxical effects of maternal stress on fetal steroid and postnatal reproductive traits in female mice from different intrauterine position Biology of Reproduction 43 751-761 
vom Saal FS, Montano MM and Wang H-S (1992) Sexual differentiation in mammals. In Chemically Induced Alterations in Sexual and Functional Development: The Wildlife-Human Connection Eds T Colborn and C Clement. Princeton Scientific Pub., Princeton, NJ, 17-83

Ward I and Weisz J (1980) Maternal stress alters plasma testosterone in fetal males Science 207 328-329

Wilke D, Tsue S, Rhees $\mathbf{R}$ and Fleming D (1982) Effects of environmental stress or ACTH treatment during pregnancy on maternal and fetal plasma androstenedione in the rat Hormones and Behavior 16 293-303
Wong MD and Burton AF (1974) Studies on corticosterone-receptor complexes from mouse placenta Canadian Journal of Biochemistry 52 190-195

Yamamoto M, Eguchi Y, Asari M and Kano Y (1983) Developmental changes in fetal adrenal hypertrophy following maternal bilateral and fetal unilateral adrenalectomy at different stages of gestation in the rat Biology of the Neonate 43 43-49

Zarrow MX, Philpott JE and Denenberg VH (1970) Passage of ${ }^{14} \mathrm{C}$-corticosterone from the rat mother to the fetus and neonate Nature 2261058 